\title{
Analysis of Acrolein Exposure Induced Pulmonary Response in Seven Inbred Mouse Strains and Human Primary Bronchial Epithelial Cells Cultured at Air-Liquid Interface
}

\author{
Gunnar Johanson, ${ }^{1}$ Aishwarya Mishra Dwivedi, ${ }^{1}$ Lena Ernstgård, ${ }^{1}$ Lena Palmberg, \\ Koustav Ganguly, ${ }^{1}$ Lung Chi Chen, ${ }^{2}$ Karen Galdanes, ${ }^{2}$ Terry Gordon, \\ and Swapna Upadhyay $\mathbb{D}^{1}$
}

${ }^{1}$ Integrative Toxicology, Institute of Environmental Medicine, Karolinska Institute, Stockholm, Sweden

${ }^{2}$ Department of Environmental Medicine, NYU, School of Medicine, USA

Correspondence should be addressed to Swapna Upadhyay; swapna.upadhyay@ki.se

Received 3 July 2020; Revised 7 September 2020; Accepted 15 September 2020; Published 14 October 2020

Academic Editor: J rgen B nger

Copyright (c) 2020 Gunnar Johanson et al. This is an open access article distributed under the Creative Commons Attribution License, which permits unrestricted use, distribution, and reproduction in any medium, provided the original work is properly cited.

\begin{abstract}
Background. Acrolein is a major component of environmental pollutants, cigarette smoke, and is also formed by heating cooking oil. We evaluated the interstrain variability of response to subchronic inhalation exposure to acrolein among inbred mouse strains for inflammation, oxidative stress, and tissue injury responses. Furthermore, we studied the response to acrolein vapor in the lung mucosa model using human primary bronchial epithelial cells (PBEC) cultured at an air-liquid interface (ALI) to evaluate the findings of mouse studies. Methods. Female 129S1/SvlmJ, A/J, BALB/cByJ, C3H/HeJ, C57BL/6J, DBA/2J, and FVB/NJ mice were exposed to 1 part per million ( $\mathrm{ppm}$ ) acrolein or filtered air for 11 weeks. Total cell counts and protein concentrations were measured in bronchoalveolar lavage (BAL) fluid to assess airway inflammation and membrane integrity. PBEC-ALI models were exposed to acrolein vapor $(0.1$ and $0.2 \mathrm{ppm})$ for 30 minutes. Gene expression of proinflammatory, oxidative stress, and tissue injury-repair markers was assessed (cut off: $\geq 2$ folds; $p<0.05$ ) in the lung models. Results. Total BAL cell numbers and protein concentrations remained unchanged following acrolein exposure in all mouse strains. BALB/cByJ, C57BL/6J, and 129S1/SvlmJ strains were the most affected with an increased expression of proinflammatory, oxidative stress, and/or tissue injury markers. $\mathrm{DBA} / 2 \mathrm{~J}, \mathrm{C} 3 \mathrm{H} / \mathrm{HeJ}, \mathrm{A} / \mathrm{J}$, and $\mathrm{FVB} / \mathrm{NJ}$ were affected to a lesser extent. Both matrix metalloproteinase $9(\mathrm{Mmp} 9)$ and tissue inhibitor of metalloproteinase 1 (Timp1) were upregulated in the strains DBA/2J, C3H/HeJ, and FVB/NJ indicating altered protease/antiprotease balance. Upregulation of lung interleukin- (IL-) $17 b$ transcript in the susceptible strains led us to investigate the IL-17 pathway genes in the PBEC-ALI model. Acrolein exposure resulted in an increased expression of $I L-17 A$, $C$, and $D ; I L-1 B ; I L-22$; and RAR-related orphan receptor $A$ in the PBEC-ALI model. Conclusion. The interstrain differences in response to subchronic acrolein exposure in mouse suggest a genetic predisposition. Altered expression of IL-17 pathway genes following acrolein exposure in the PBEC-ALI models indicates that it has a central role in chemical irritant toxicity. The findings also indicate that genetically determined differences in IL-17 signaling pathway genes in the different mouse strains may explain their susceptibility to different chemical irritants.
\end{abstract}

\section{Introduction}

Acrolein (2-propenal) is a highly volatile and reactive $\alpha-\beta$ unsaturated aldehyde that is primarily used as an intermediate in chemical manufacturing [1]. It is also produced during endogenous oxidative processes and is a major bioactive component of environmental pollutants such as automobile exhaust, biomass fuel, burning of wood and plastics, and smog. Acroleins are also formed by heating cooking oil and fat (above $300^{\circ} \mathrm{C}$ ) during domestic cooking [2]. Acrolein is an important constituent of mainstream cigarette smoke with concentrations about $90 \mathrm{ppm}$ [3]. The major effects of 
inhalation exposure to acrolein in humans and animals result in eye, nose, and throat irritation. Nasal irritation, activation of sensory nerves in the nasal mucosa, increaseexposure (0.31-1.7 ppm) in rodent studies [2].

Several in vivo studies have demonstrated that acute exposure to 0.2 to $6 \mathrm{ppm}$ acrolein causes pulmonary edema, stimulates sensory nerves and airway cell proliferation, and diminishes pulmonary defenses against bacterial and viral infection [4]. Leikauf et al. [5] performed a study exposing 40 inbred mouse strains to $10 \mathrm{ppm}$ acrolein to induce acute lung injury [1]. The study demonstrated remarkable variation in survival times among the mouse strains ( $<20 \mathrm{~h}: 13$ strains; 20-30 h: 20 strains; $>30 \mathrm{~h}: 7$ strains) following acrolein-induced acute lung injury. The study was extended to identify genes that may render susceptibility or resistance to acrolein-induced acute lung injury by comparing the polar strains. Acute lung injury is a sporadic event, and case-based observation suggests great variability in individual susceptibility; i.e., individuals with the same severity score can have markedly different clinical outcomes thereby suggesting a high degree of genetic predisposition [5].

Borchers et al. [6] examined the effect of 0.01-100 nM acrolein on mucin gene expression in cultured human airway epithelial cells. Increased mucin (MUC5AC) transcript levels following a $4 \mathrm{~h}$ exposure to acrolein in cultured human airway epithelial cells were reported. Inflammation, oxidative stress, and tissue destruction are considered as primary adverse outcome pathways of most chronic lung diseases (McGuinness and Sapey [7]). Therefore, in this study, we sought to investigate variability in pulmonary response to subchronic acrolein exposure among seven inbred mouse strains measured as oxidative stress, proinflammatory response, and tissue injury. The study was aimed at investigating acrolein as an irritant model substance with a plausible genetic susceptibility contribution. The survival time of the seven inbred mouse strains selected for our study was spread across the survival times of the 40 inbred mouse strains (female) observed by Leikauf et al. [5]. together with easy availability and common use in respiratory research. Based on our findings of altered lung interleukin-17B (IL-17B) transcript expression in acrolein-exposed mice, we further investigated the IL-17 pathway genes in the human primary bronchial epithelial cells (PBEC) cultured at an air-liquid interface (ALI) following 0.1 and 0.2 parts per million (ppm) acrolein exposure.

\section{Methods}

2.1. Animals. Female 129S1/SvlmJ (stock number 002448), A/J (stock number 000646), BALB/cByJ (stock number 001026), C3H/HeJ (stock number 000659), C57BL/6J (stock number 000664), DBA/2J (stock number 000671), and FVB/NJ (stock number 001800) mice (age: 10 weeks) were obtained from the Jackson Laboratory (Bar Harbor, ME, USA), housed under specific pathogen-free conditions at the animal facility of the New York University, School of Medicine (NY, USA), and quarantined for at least 2 weeks before study initiation. Food and water were provided ad libitum except during exposure. The study was approved by the
Institutional Animal Care and Use Committee, New York University, School of Medicine (NY, USA). We used only female mice for our study to minimize the animal numbers and for comparative analyses with other studies [5].

\subsection{Mouse Procedures}

2.2.1. Acrolein Exposure. Mice ( $n=5$ /group/strain) were exposed to filtered air or acrolein vapor via whole-body exposure in $1.3 \mathrm{M}^{3}$ stainless steel inhalation exposure chambers for 6h/day, 4-5 days/week for a total of 11 weeks. Acrolein vapor was generated by passing charcoal and HEPA-filtered air over acrolein (Sigma Chemical Co.) in a glass flask. The chamber concentration of acrolein was monitored on an hourly basis on each exposure day (target concentration of $1 \mathrm{ppm}$ ) with a Miran $1 \mathrm{~A}$ single-beam infrared spectrometer (Foxboro Analytical, Foxboro, MA). The actual chamber concentration was $1.03 \pm 0.03 \mathrm{ppm}$ (mean $\pm \mathrm{SD}$ ). The $1 \mathrm{ppm}$ dosage was a high dose to start with and nonlethal for a repeated exposure study, and in addition, it was an order of magnitude lower than that used in acute lung injury exposure studies.

2.2.2. Bronchoalveolar Lavage (BAL). At $24 \mathrm{~h}$ after the final exposure, mice were euthanized by intraperitoneal injections of ketamine $\mathrm{HCl}$ (100 mg/kg; Vetalar, Fort Dodge Laboratories, Fort Dodge, IA) and sodium pentobarbital $(175 \mathrm{mg} / \mathrm{kg}$; Sleepaway, Fort Dodge Laboratories), and the posterior abdominal aorta was severed. The lungs of each mouse were lavaged two times with $1.2 \mathrm{ml}$ of Dulbecco's phosphatebuffered saline without $\mathrm{Ca}$ or $\mathrm{Mg}\left(\mathrm{pH} 7.2-7.4,37^{\circ} \mathrm{C}\right.$; GibcoBRL, Life Technologies, Grand Island, NY). The recovered BAL fluid was immediately placed on ice $\left(4^{\circ} \mathrm{C}\right)$. The lavage fluid was then centrifuged $\left(500 \mathrm{x} \mathrm{g}, 8 \mathrm{~min}, 4^{\circ} \mathrm{C}\right)$, and the supernatant was pipetted off. The total protein concentration in the supernatant was measured using an assay kit that follows the method of Bradford (1976) [8] (bovine serum albumin standard, $550 \mathrm{~nm}$; Pierce, Rockford, IL). The total protein concentration in BAL fluid was used as an indicator of changes in lung permeability and injury [9]. Total cell counts were determined with a hemacytometer.

\subsubsection{Lung Transcript Expression Analysis. Total lung RNA} was isolated using the RNeasykit (catalog number 74104; Qiagen, Hilden, Germany) according to the manufacturer's instruction, and the concentration was quantified using Nanodrop 2100 (ThermoFisher, USA). The extracted total RNA was stored at $-80^{\circ} \mathrm{C}$ until further use (supplementary file). Transcripts assayed using the qRT-PCR technique included beta actin $(A c t b)$, chemokine (C-X-C motif) ligand 1 (Cxcl1), Cxcl2, glutathione peroxidase 1 and 3 (Gpx1, Gpx3), heme oxygenase 1 (Hmox1), interleukin-6 (IL-6), IL$17 B$, matrix metalloproteinase $9(\mathrm{Mmp} 9)$, nuclear factor of kappa light polypeptide gene enhancer in B cells 1, p105 (Nfkb1), superoxide dismutase 3, extracellular (Sod3), tissue inhibitor of metalloproteinase 1 (Timp1), and tumor necrosis factor (Tnf). Beta actin (Actb) was used as the reference control. Forward and reverse primer sequences are provided in supplementary Table S1. 


\section{Air-Liquid Interface (ALI) Model Development}

The human airway mucosa model was developed using PBEC from 3 individual $(N=3)$ donors and cultured at ALI as previously described [10-12]. All procedures performed in this study were in accordance with the approval of the Ethics Committee of Karolinska Institutet, Stockholm. The PBEC that we have used in this study are well characterized and used in several previous studies $[13,14]$. PBEC from passages 3 or 4 were grown under submerged conditions in Petri dishes and were cultured up to $80 \%$ confluency at $37^{\circ} \mathrm{C}$ in a humidified atmosphere of $5 \% \mathrm{CO}_{2}$ using a serumfree keratinocyte medium (KSFM; Gibco, USA) supplemented with $5 \mathrm{ng} / \mathrm{ml}$ epidermal growth factor (EGF; Gibco, USA), $50 \mu \mathrm{g} / \mathrm{ml}$ bovine pituitary extract (BPE; Gibco, USA), and $20 \mathrm{U} / \mathrm{ml}$ pen/strep (Gibco, USA). The medium was changed every second day. Cells from the Petri dishes were trypsinized, resuspended, and seeded on precoated $0.4 \mu \mathrm{m}$ semiporous transwell inserts (BD Falcon ${ }^{\mathrm{TM}}$, USA), placed in twelve well plates at a density of 0.1 million cells/well. The inserts were maintained in submerged conditions with $1 \mathrm{ml}$ complete KSFM on both (inner and outer) sides of inserts. Once cells reached $90 \%$ confluence, the inserts were turned upside down and put in a sterile Petri dish to add MRC-5 cells (Medical Research Council cell strain 5, fibroblasts derived from human lung tissue) in a complete Dulbecco's Modified Eagle's Medium to the outer or basal side of the insert membrane [10]. After 30 minutes of incubation, the inserts were again placed in the plate with $1 \mathrm{ml}$ of complete KSFM per well, on both inner (apical) and outside (basal side) of the insert. The next day, the models were air-lifted by removing the medium and adding $870 \mu \mathrm{l}$ coculture medium (i.e., complete KSFM with $6 \mu \mathrm{g} / \mathrm{ml} \mathrm{CaCl}_{2}$ in double-distilled water $\left(\mathrm{ddH}_{2} \mathrm{O}\right), 15 \mathrm{ng} / \mathrm{ml}$ ethanolamine in $\mathrm{ddH}_{2} \mathrm{O}$, and $10-5 \mathrm{M}$ retinoic acid) basal or outside the insert. The cells were incubated at $37^{\circ} \mathrm{C}$ with $5 \% \mathrm{CO}_{2}$ for at least two weeks till they began to differentiate into different cell types: mucus-producing cells, ciliated cells and club cells, and basal cells. Three technical replicates $(n=3 /$ donor/acrolein concentration) were developed from each donor and were exposed for 30 minutes to different concentrations of acrolein vapor separately (see below). Finally, the expression of genes within the IL-17 pathway was analyzed at $24 \mathrm{~h}$ postexposure to acrolein.

3.1. Acrolein Exposure of the ALI Model. Three technical replicates developed from each donor were exposed for 30 minutes to clean air (sham), 0.05, 0.1, 0.2, and $0.5 \mathrm{ppm}(0$, $0.1,0.2,0.5$, and $1.1 \mathrm{mg} / \mathrm{m}^{3}$ ) acrolein using our in-house developed exposure systems as described in previous studies $[10,12]$. The actual acrolein concentrations in the ALI chamber air were monitored by gas chromatography (five times during 30 minutes), as described previously [10], and were on average $17-25 \%$ higher than the target concentrations. Cell viability of PBEC was tested at $24 \mathrm{~h}$ after exposure by trypan blue staining $(200 \mu \mathrm{l}$ of $1: 1$ in PBS diluted $0.4 \%$ trypan blue solution for 1 minute), washing by PBS, and followed by bright-field microscopy [10]. At $0.5 \mathrm{ppm}$, cell viability was $70 \% \pm 5 \%$ (mean \pm SD) [10]. Since none of the other doses showed any cytotoxicity [2], further analysis was carried out in 0.1 and $0.2 \mathrm{ppm}$ acrolein-exposed samples compared to sham. Based on the findings of altered $\mathrm{Il}-17 \mathrm{~B}$ regulation in the mouse lungs following subchronic acrolein exposure, we explored the IL-17 pathway in acroleinexposed PBEC. Transcript expression of $I L-17 A, I L-17 B, I L-$ $17 C, I L-17 D, I L-17 E, I L-1 B, I L-22$, RAR-related orphan receptor $\mathrm{A}(R O R A)$, and signal transducer and activator of transcription 3 (STAT3) was analyzed $24 \mathrm{~h}$ after the $30 \mathrm{~min}$ exposure to clean air (sham), 0.1 and 0.2 ppm acrolein. Forward and reverse primer sequences are provided in supplementary table S1.

3.2. Statistical Analyses. The results are generally expressed as medians and interquartile ranges (25th-75th percentiles) normalized with its own sham (control). For the in vivo study, the Friedman test was used to analyze differences between sham (clean air: control) and acrolein-exposed animals of each strain. Additionally, the interstrain differences of in vivo studies were compared by Kruskal-Wallis followed by Mann-Whitney. Similarly, for in vitro study, the Friedman test was used to analyze differences between sham (clean air: control) and different concentrations of acrolein used to expose the in vitro ALI model, followed by the Wilcoxon signed-rank $t$ test as a post hoc test. A $p$ value $<0.05$ was considered as statistically significant. All data were analyzed using the STATISTICA13 software (StatSoft, Inc., Uppsala, Sweden). The statistical analysis of transcript expression was carried out using the dCT values.

\section{Results}

4.1. BAL Analysis. Total BAL cell counts and protein concentrations showed no changes in the acrolein-exposed mice compared to their respective strain control exposure (supplementary Table S2 and Table S3).

4.2. Transcript Expression in Mouse Lungs. The BALB/cByJ, C57BL/6J, and 129S1/SvlmJ mouse strains exhibited the highest increase in mRNA expression levels for both oxidative stress (Gpx1, Gpx3, Nfkb1, and Sod3; 2-5 fold; Figures 1(a)-1(e)) and proinflammatory markers (Cxcl1, Cxcl2, IL-6, IL-17B, and Tnf: 2 - to 4-fold, Figures 2(a)2(e)). High oxidative stress response (Gpx1: 2-fold increased and Sod3: >4-fold increased; Figures 1(a) and 1(e)) was also detected in $\mathrm{C} 3 \mathrm{H} / \mathrm{HeJ}$ compared to a comparatively low oxidative stress response in $\mathrm{DBA} / 2 \mathrm{~J}$ and $\mathrm{FVB} / \mathrm{NJ}$ strains (Figure 1(a)). Interestingly, the oxidative stress marker Hol did not show any significant alteration in any of the investigated seven inbred mouse strains exposed to subchronic doses of acrolein (Figure 1(d)). The A/J and FVB/NJ strains exhibited a medium proinflammatory response as observed by $\sim 2$-fold increase of $\operatorname{Tnf}, \mathrm{Cxcl} 1, \mathrm{Cxcl} 2$, and IL-6 transcripts (Figures 2(a)-2(e)). C3H/HeJ and $\mathrm{DBA} / 2 \mathrm{~J}$ mice did not show any alteration in these proinflammatory markers.

To determine the effect of acrolein exposure on proteinase and antiproteinase homeostasis, measurements of the 


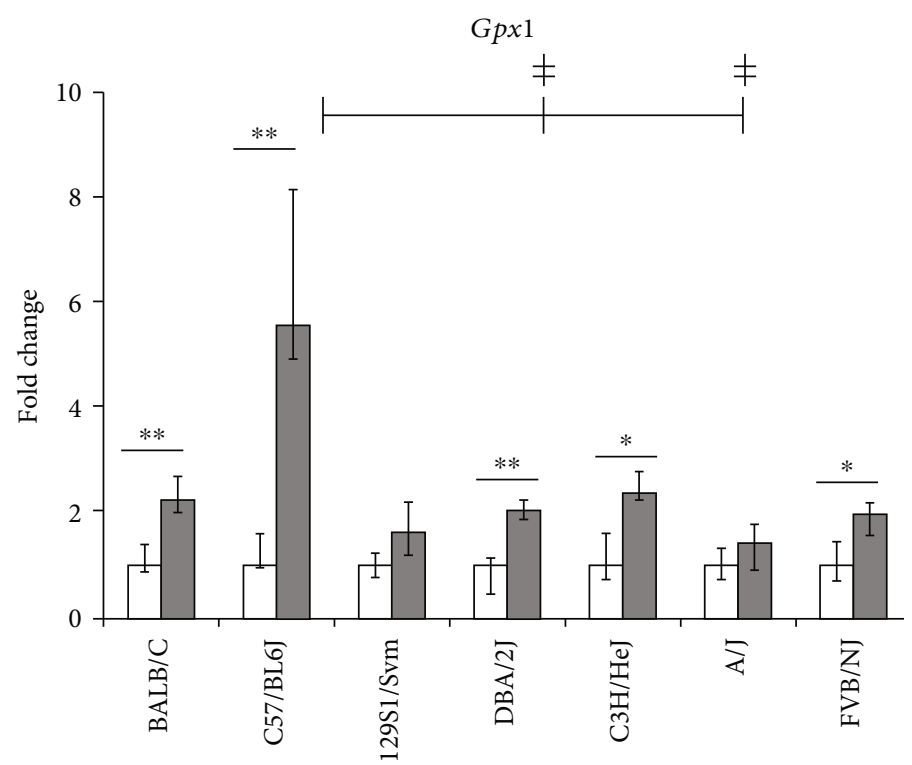

(a)

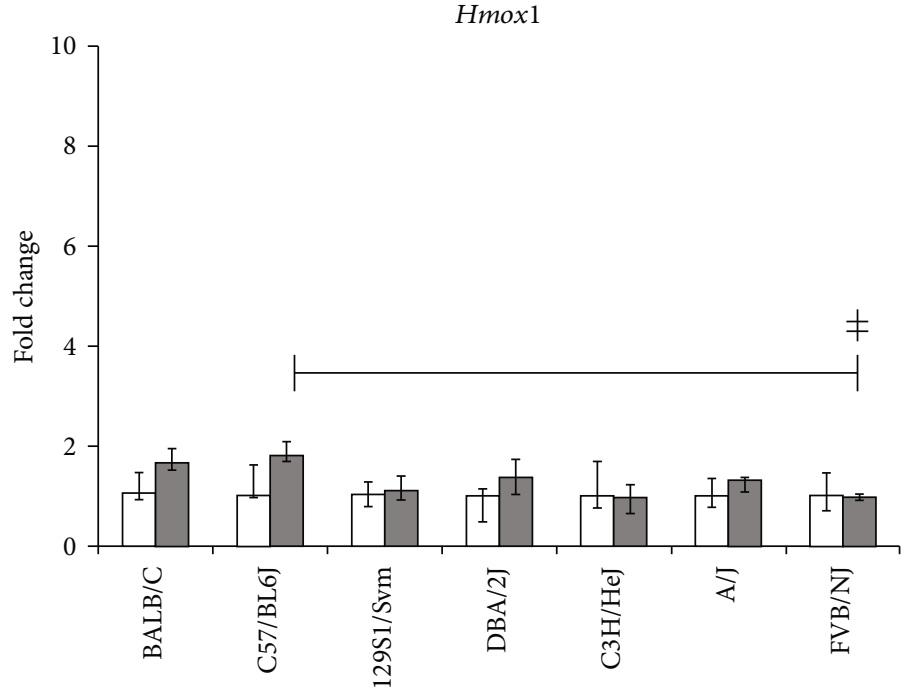

(b)

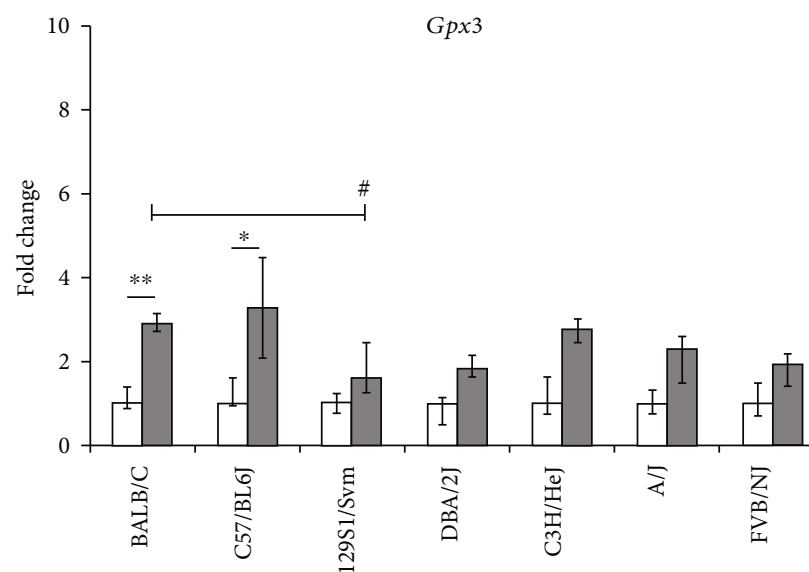

(c)

Figure 1: Continued. 


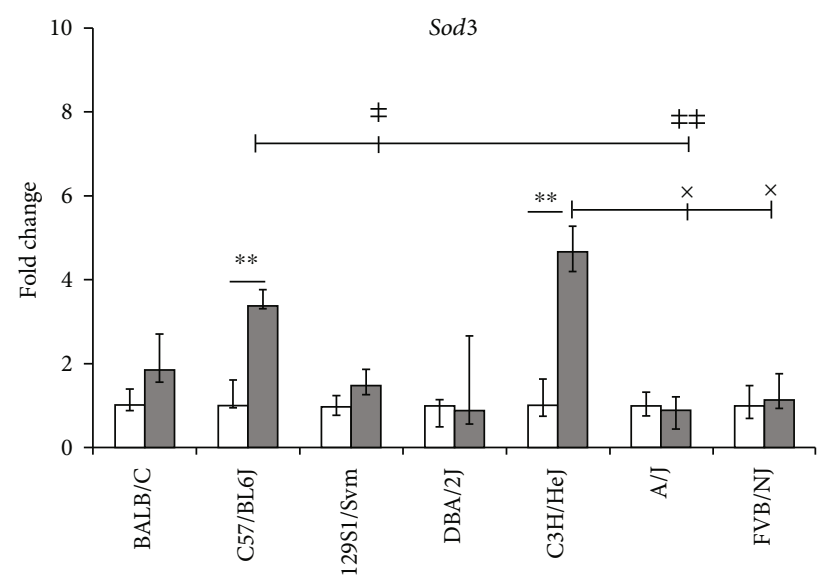

(d)

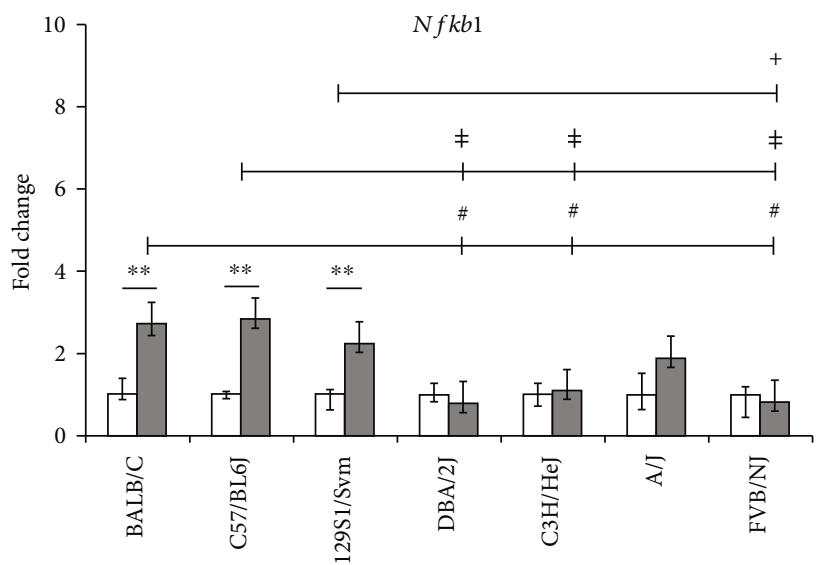

(e)

FIGURE 1: Lung transcript analysis of oxidative stress markers in seven mouse strains exposed to clean air (sham) or acrolein (1 ppm, 6 hours/day, 4-5 days/week for 11 weeks): (a) glutathione peroxidase 1 (Gpx1); (b) glutathione peroxidase 3 (Gpx3); (c) superoxide dismutase 3, extracellular (Sod3); (d) heme oxygenase 1 (Hmox1); (e) nuclear factor of kappa light polypeptide gene enhancer in B cells 1, p105 (Nfkb1). Beta actin (Actb) served as the housekeeping control gene. Data are presented as an expression in the exposed group relative to age and strain-matched sham-exposed group (median and 25th-75th percentiles; $n=5 \mathrm{mice} / \mathrm{strain} / \mathrm{stage}$ ); white bars: sham, gray bars: acrolein exposed. ${ }^{*} p$ value $<0.05$ and ${ }^{* *} p$ value $<0.01$; sham vs. exposed group of each strain. ${ }^{*} p$ value $<0.05$, exposed BALB/cByJ vs. other exposed strains like DBA/2J, C3H/HeJ, and $\mathrm{A} / \mathrm{J} .{ }^{\ddagger} p$ value $<0.05$ and ${ }^{\neq \neq} p$ vaue $<0.01$; exposed $\mathrm{C} 57 \mathrm{BL} / 6 \mathrm{~J}$ vs. exposed strains like $\mathrm{DBA} / 2 \mathrm{~J}, \mathrm{C} 3 \mathrm{H} / \mathrm{HeJ}$, and FVB/NJ. ${ }^{+} p$ value $<0.05$, exposed $129 \mathrm{~S} 1 / \mathrm{SvlmJ}$ vs. exposed FVB/NJ. ${ }^{\mathrm{x}} p$ value $<0.05$, exposed C3H/HeJ vs. exposed $\mathrm{A} / \mathrm{J}$ vs. FVB/NJ.

expression of $M m p 9$ and Timp1 were performed (Figures 3(a) and 3(b)). Mmp9 was increased in BALB/cByJ, $\mathrm{C} 3 \mathrm{H} / \mathrm{HeJ}$, and $\mathrm{DBA} / 2 \mathrm{~J}$ by $\sim 2$-fold (Figure 3(a)), and a corresponding $>3$-fold increase in Timp1 was detected in the lungs of $\mathrm{C} 3 \mathrm{H} / \mathrm{HeJ}$ and $\mathrm{DBA} / 2 \mathrm{~J}$ but not in $\mathrm{BALB} / \mathrm{cByJ}$ mice (Figure 3(b)). Timp1 expression was also increased by $\sim 2-$ fold in FVB/NJ mice. Basal lung transcript levels of some selected oxidative stress, proinflammatory, and extracellular matrix markers among the seven inbred mouse strains are shown in Table 1. None of the genes exhibited any statistically significant difference in their transcript expression among the sham-exposed groups. The interstrain difference in transcript expression of the investigated genes following acrolein exposure is shown in Figures 1-3.

4.3. Analysis of the $I L-17$ Pathway. Significantly increased expression of $I L-17 B$ was detected in the BALB/cByJ, $\mathrm{C} 57 \mathrm{BL} / 6 \mathrm{~J}$, and $129 \mathrm{~S} 1 / \mathrm{Sv}$ lm J mouse strains following sub- chronic exposure to $1 \mathrm{ppm}$ acrolein. IL-17, the signature cytokine secreted by Th17 cells, is required for host defense mechanisms. Altered regulation of IL-17-related cytokines can contribute to the pathogenesis of various inflammatory diseases [15]. Therefore, in this study, we further explored the transcript expression pattern of several key IL-17 cytokine family members ( $I L-17 A, B, C, D$, and F; Figures 4(a)$4(\mathrm{e})) 24 \mathrm{~h}$ postexposure to 0.1 and $0.2 \mathrm{ppm}$ acrolein vapor in PBEC cultured at ALI condition. Additionally, we have also analyzed the expression of RORA, STAT3, IL-1B, and $I L-22$ which are also considered important members of the IL-17 family. Figure 4 exhibits the significantly increased expression of $I L-17 A$ (Figure 4(a)) and IL-17C (Figure 4(c)) in PBEC following exposure to both 0.1 and $0.2 \mathrm{ppm}$ acroleins compared to sham. The expression of $I L-17 D$ was significantly upregulated after exposure to $0.1 \mathrm{ppm}$ acrolein (Figure $4(\mathrm{~d})$ ), similar to the expression of $I L-17 \mathrm{C}$ following exposure to $0.2 \mathrm{ppm}$ acrolein. In general, the expression of 


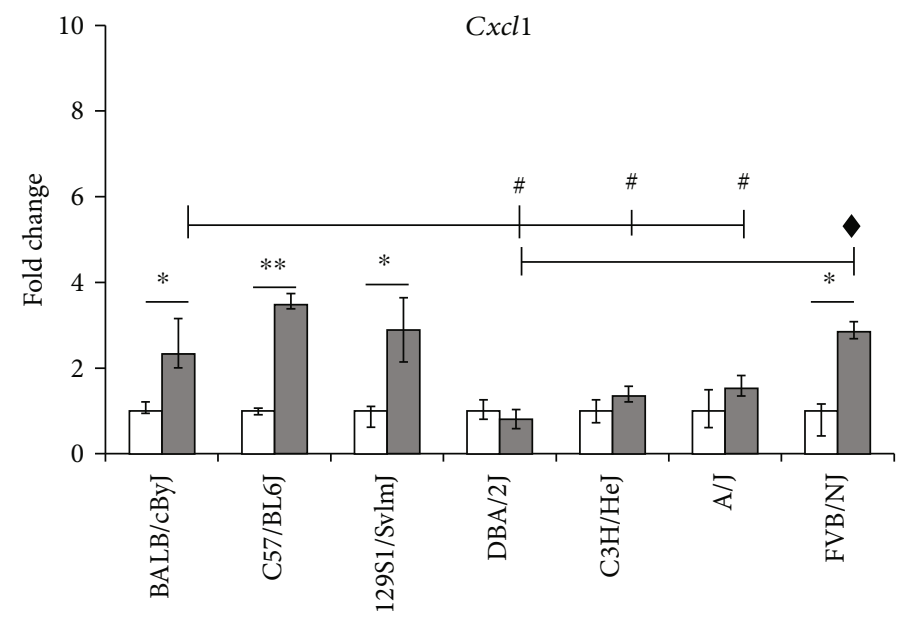

(a)

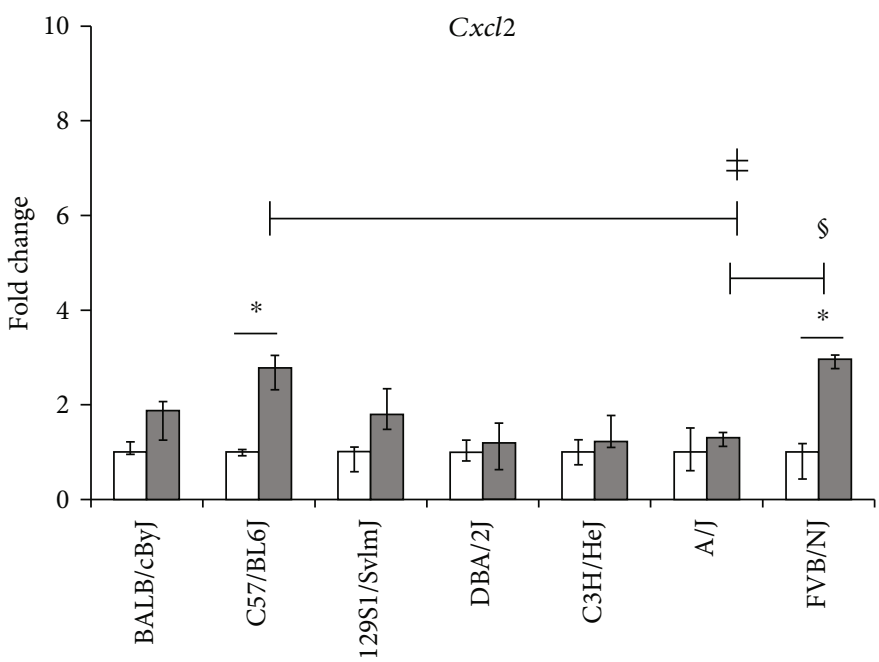

(b)

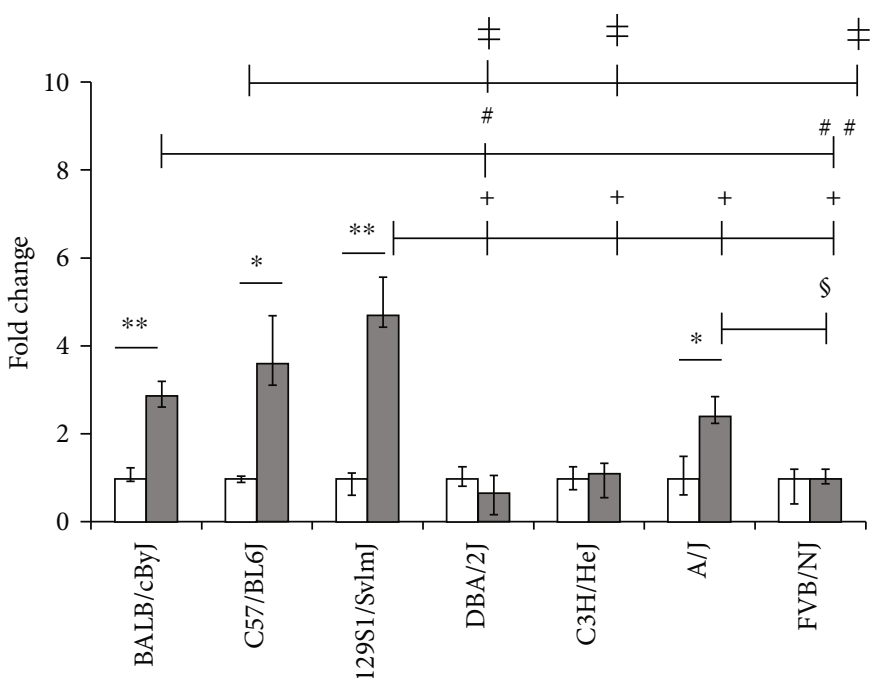

(c)

Figure 2: Continued. 


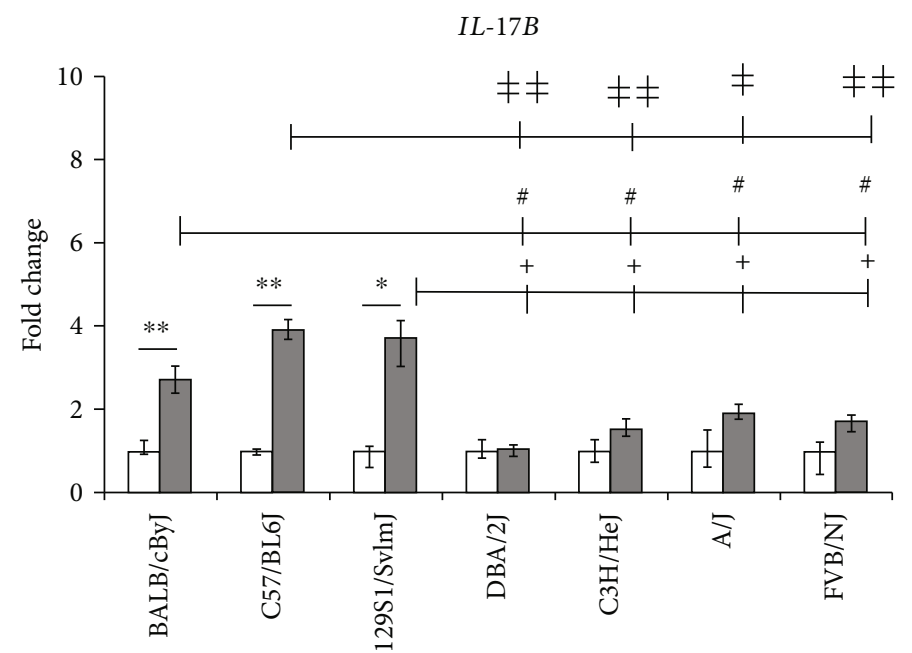

(d)

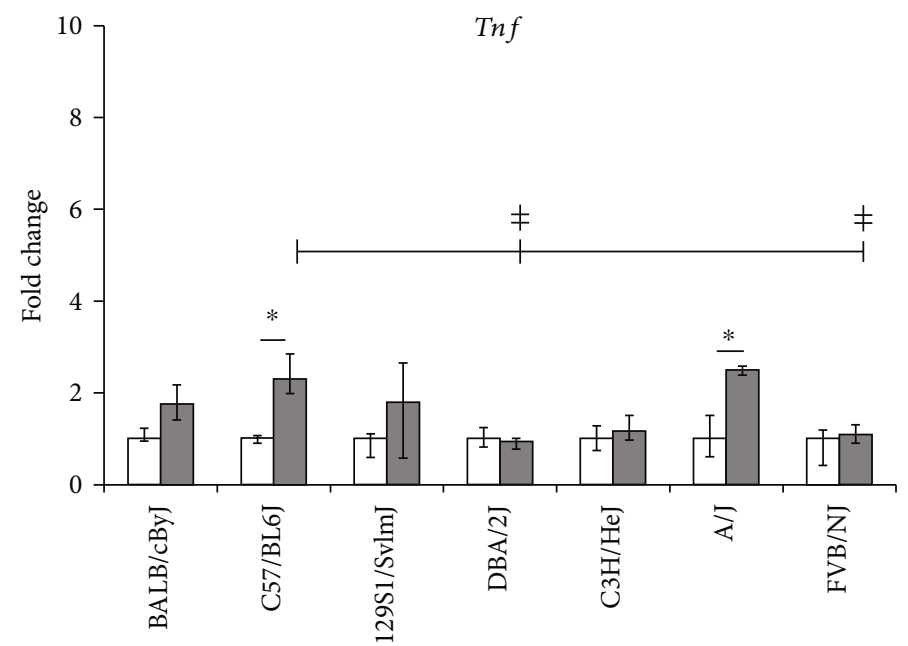

(e)

FiguRe 2: Lung transcript analysis of proinflammatory markers in seven mouse strains exposed to clean air (sham) or acrolein (1 ppm, 6 hours/day, 4-5 days/week, 11 weeks): (a) chemokine (C-X-C motif) ligand 1 (Cxcl1); (b) chemokine (C-X-C motif) ligand 2 (Cxcl2); (c) interleukin-6 (IL-6); (d) interleukin-17B (IL-17B); (e) tumor necrosis factor (Tnf). Beta actin (Actb) served as the control. Data are presented as an expression in the exposed group relative to age and the strain-matched sham-exposed group (median and 25th-75th percentiles; $n=5$ mice/strain/stage). Mouse strains: 129S1/SvlmJ, A/J, BALB/cByJ, C3H/HeJ, C57BL/6J, DBA/2J, and FVB/NJ; white bars: sham, gray bars: acrolein exposed. ${ }^{*} p$ value $<0.05$ and ${ }^{* *} p<0.01$; sham vs. exposed group of each strain. ${ }^{\#} p<0.05$ and ${ }^{\# \#} p<0.01$; exposed $\mathrm{BALB} / \mathrm{cByJ}$ vs. other exposed strains like DBA/2J, C3H/HeJ, and $\mathrm{A} / \mathrm{J} .{ }^{\ddagger} p$ value $<0.05$ and ${ }^{\ddagger \neq} p$ value $<0.01$; exposed C57BL/6J vs. exposed strains like DBA/2J, C3H/HeJ, and $\mathrm{FVB} / \mathrm{NJ} .{ }^{+} p$ value < 0.05, exposed $129 \mathrm{~S} 1 / \mathrm{SvlmJ}$ vs. exposed strains $\mathrm{DBA} / 2 \mathrm{~J}, \mathrm{C} 3 \mathrm{H} / \mathrm{HeJ}, \mathrm{A} / \mathrm{J}$, and $\mathrm{FVB} / \mathrm{NJ} .{ }^{\star} p$ value $<0.05$, exposed DBA/2J vs. exposed. ${ }^{\S} p$ value $<0.05$, exposed A/J vs. exposed FVB/NJ.

most of the IL-17 isotypes exhibited a stronger response at $0.1 \mathrm{ppm}$ acrolein compared to $0.2 \mathrm{ppm}$. Furthermore, $I L-1 B$ showed significantly reduced expression at both 0.1 and $0.2 \mathrm{ppm}$ acroleins (Figure 5(a)). While the expression of RORA and $I L-22$ was significantly increased at $0.1 \mathrm{ppm}$ acrolein (Figures 5(b) and 5(c)), and STAT3 expression remained unaltered at both 0.1 and $0.2 \mathrm{ppm}$ acroleins (Figure 5(d)).

\section{Discussion}

Acrolein- (10 ppm) induced acute lung injury in female mice has shown that the survival time among the most polar strains varied approximately 2.5 -fold from $16 \mathrm{~h}$ (susceptible) to $41 \mathrm{~h}$ (resistant). Furthermore, based on survival time, the
40 inbred strains can be broadly categorized into three groups: (i) <20 h: 13 strains, (ii) 20-30 h: 20 strains, and (iii) $\geq 30$ h: 7 strains. These findings strongly support the genetic predisposition to acrolein-induced acute lung injury among mice. The survival time of our investigated 7 strains to acrolein-induced acute lung injury was in the following order BALB/cByJ $\quad(<20 \mathrm{~h})<\mathrm{C} 57 \mathrm{BL} / 6 \mathrm{~J}<129 \mathrm{~S} 1 /$ SvlmJ $<$ DBA $/ 2 \mathrm{~J}<$ $\mathrm{C} 3 \mathrm{H} / \mathrm{HeJ}<\mathrm{A} / \mathrm{J}(20-30 \mathrm{~h})<\mathrm{FVB} / \mathrm{NJ}(>30 \mathrm{~h})$ [5]. Therefore, the selected mouse strains in this project were spread across the three broad categories of survival time for acroleininduced acute lung injury. We investigated markers of three key events of adverse outcome pathways for chronic lung diseases, namely, oxidative stress, inflammation, and tissue injury/repair in the lungs of the 7 inbred mouse strains 


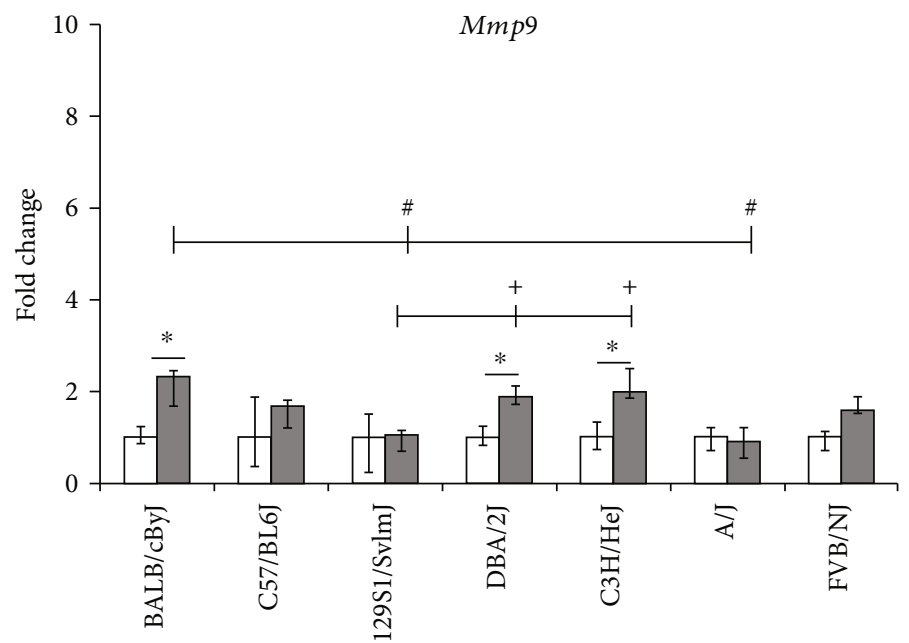

(a)

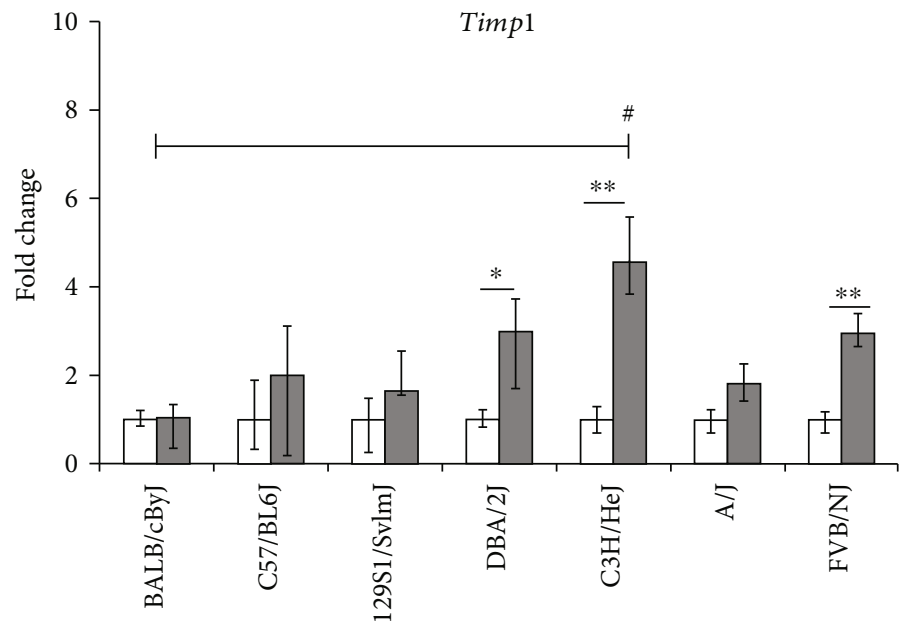

(b)

FIGURE 3: Lung transcript analysis of tissue injury markers in seven mouse strains exposed to clean air (sham) or acrolein (1 ppm, 6 hours/day, 4-5 days/week, 11 weeks): (a) matrix metallopeptidase 9 (Mmp9); (b) tissue inhibitor of metalloproteinase 1 (Timp1). Beta actin (Actb) served as the control. Data are presented as an expression in the exposed group relative to age and the strain-matched sham-exposed group (median and 25th-75th percentiles; $n=5$ mice/strain/stage). Mouse strains: 129S1/SvlmJ, A/J, BALB/cByJ, C3H/HeJ, C57BL/6J, DBA/2J, and FVB/NJ; white bars: sham; gray bars: acrolein exposed. ${ }^{*} p$ value $<0.05,{ }^{* *} p$ value $<0.01$ : sham vs. exposed group of each strain. ${ }^{\#} p$ value $<0.05$, exposed $\mathrm{BALB} / \mathrm{cByJ}$ vs. exposed 129S1/SvlmJ, C3H/HeJ, and A/J. ${ }^{+} p$ value $<0.05$, exposed $129 \mathrm{~S} 1 / \mathrm{SvlmJ}$ vs. exposed DBA/2J and C3H/HeJ.

TABLE 1: Fold change calculation of selected oxidative stress, proinflammatory, and tissue injury/repair markers in sham (clean air) in six mouse strains compared to one of the most sensitive mouse strains (BALB/BL6J) used in this study.

\begin{tabular}{|c|c|c|c|c|c|c|c|}
\hline Expression markers & $\mathrm{BALB} / \mathrm{cByJ}$ & C57/BL6J & 129S1/SVLMJ & $\mathrm{DBA} / 2 \mathrm{~J}$ & $\mathrm{C} 3 \mathrm{H} / \mathrm{HeJ}$ & $\mathrm{A} / \mathrm{J}$ & $\mathrm{FVB} / \mathrm{NJ}$ \\
\hline \multicolumn{8}{|l|}{ Oxidative stress } \\
\hline Hmox1 & 1 & 0.59 & 0.34 & 1.19 & 0.67 & 1.99 & 1.42 \\
\hline$N f k b 1$ & 1 & 0.95 & 1.37 & 0.53 & 1.15 & 0.46 & 1.17 \\
\hline \multicolumn{8}{|l|}{ Inflammation } \\
\hline Cxcl1 & 1 & 0.79 & 1.29 & 1.08 & 0.89 & 0.57 & 0.75 \\
\hline Cxcl2 & 1 & 0.69 & 0.59 & 0.94 & 1.08 & 1.16 & 1.23 \\
\hline$I L-6$ & 1 & 1.32 & 1.66 & 0.74 & 1.09 & 1.18 & 1.28 \\
\hline $\operatorname{Tnf}$ & 1 & 1.1 & 0.92 & 0.82 & 0.69 & 1.04 & 0.91 \\
\hline \multicolumn{8}{|l|}{ Tissue injury/repair } \\
\hline$M m p 9$ & 1 & 1.13 & 0.85 & 1.91 & 0.52 & 0.95 & 0.59 \\
\hline Timp1 & 1 & 0.87 & 0.25 & 0.55 & 0.26 & 0.39 & 0.79 \\
\hline
\end{tabular}




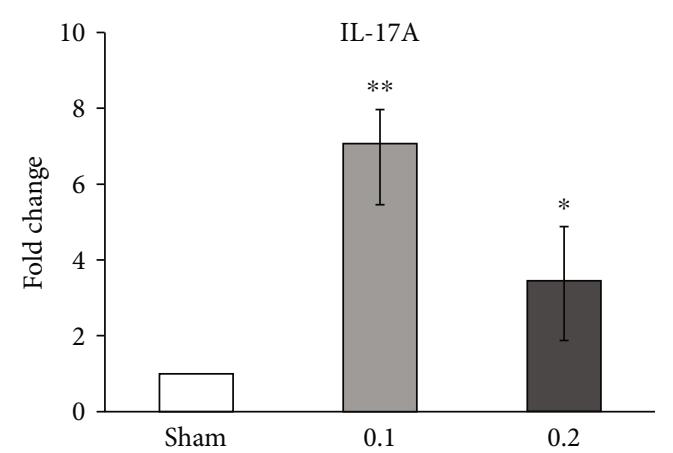

(a)

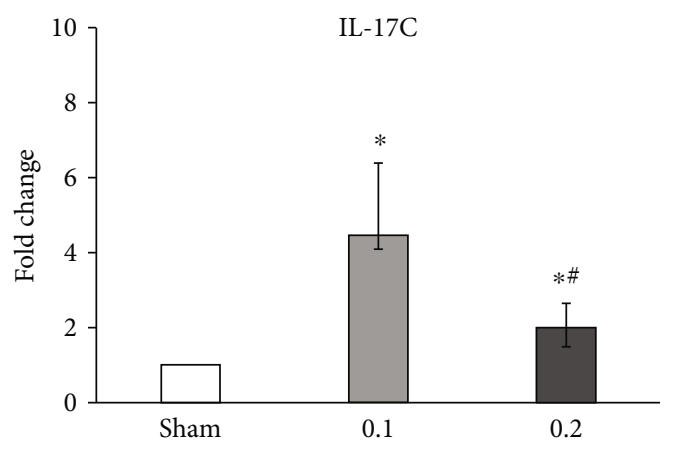

(c)

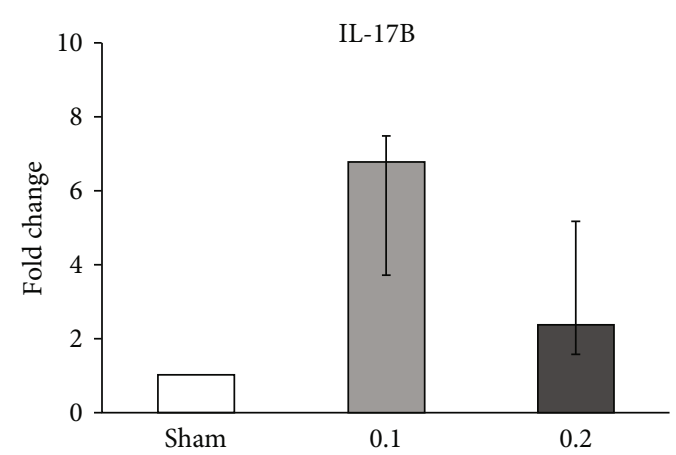

(b)

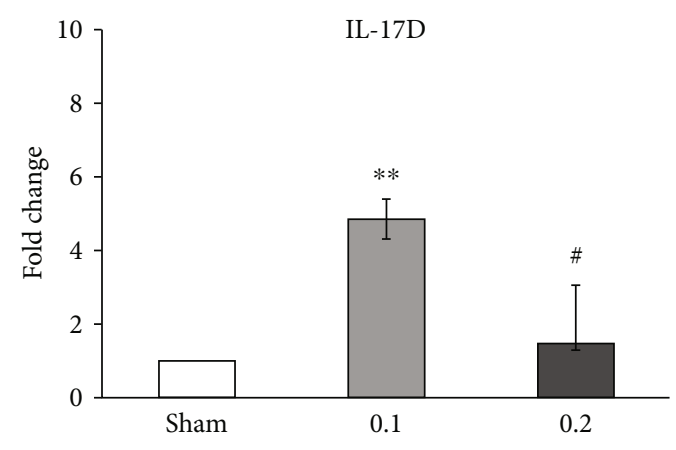

(d)

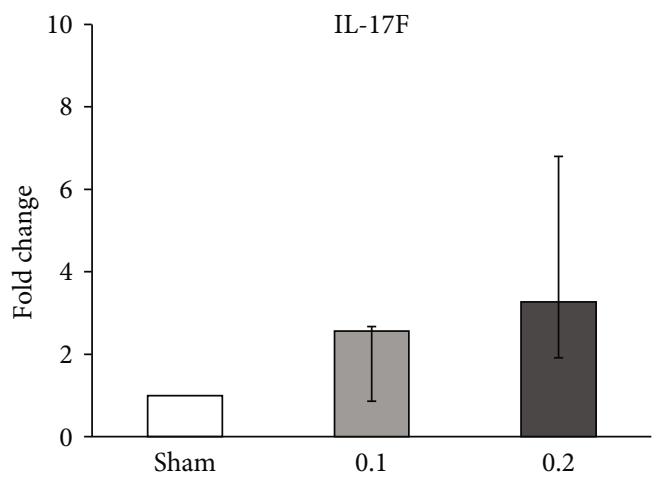

(e)

FIGURE 4: Transcript analysis of IL-17 family members (IL-17A, B, C, D, and F) in primary bronchial epithelial cells (PBEC) cultured at an airliquid interface (ALI) condition after $24 \mathrm{~h}$ incubation following a 30 -minute exposure to clean air (sham), 0.1 or $0.2 \mathrm{ppm}$ acrolein vapor: (a) interleukin-17A (IL-17A); (b) interleukin-17B (IL-17B); (c) interleukin-17C (IL-17C); (d) interleukin-17D (IL-17D); (e) interleukin-17F (IL$17 F)$. Beta actin $(A C T B)$ served as the control. Data are presented as median and 25th-75th percentiles $(N=3$ donors and $n=2$ replicates/donor). ${ }^{*} p$ value $<0.05,{ }^{* *} p$ value $<0.01$ : sham vs. exposed group; ${ }^{\#} p$ value $<0.050 .1 \mathrm{ppm}$ vs. $0.2 \mathrm{ppm}$ acrolein exposed. White bars: sham (clean air); light gray bars: $0.1 \mathrm{ppm}$; dark gray bars: $0.2 \mathrm{ppm}$ acrolein exposed.

following a 1 ppm subchronic acrolein exposure. We further attempted to rank the 7 strains based on the altered expression of these markers for susceptibility to $1 \mathrm{ppm}$ subchronic acrolein exposure. The targeted acrolein exposure concentration (1 ppm) was lower compared to indoor environmental conditions (5 ppm) due to smoking, wood burning, or cooking $[3,16]$. The findings of the oxidative stress, proinflammatory, and tissue injury markers have been summarized in Table 2 to identify the biologically plausible sensitivity and resistance parameters.

Our findings show that subchronic exposure to low concentrations ( $1 \mathrm{ppm})$ of acrolein did not cause inflammatory cell recruitment or alveolar barrier leakage as indicated by unaltered total BAL cell number and protein concentrations (Table S2 and S3). Consistent with our findings, a lack of inflammatory cell recruitment following exposure of C57BL/6J mice to acrolein (5 ppm, $6 \mathrm{~h} /$ day for up to 3 days) was also reported by Kashara et al. [3]. The authors hypothesized that acrolein-mediated reductions in cytokine production in $\mathrm{C} 57 \mathrm{BL} / 6 \mathrm{~J}$ mice may be related to decreased antibacterial or antiviral host defense which may in turn contribute to increased susceptibility to infection or chronic lung diseases [3].

Based on the observed altered expression of the analyzed genes, the BALB/cByJ, C57BL/6J, and 129S1/SvlmJ inbred strains were most affected (Figures 1-3). The strains 


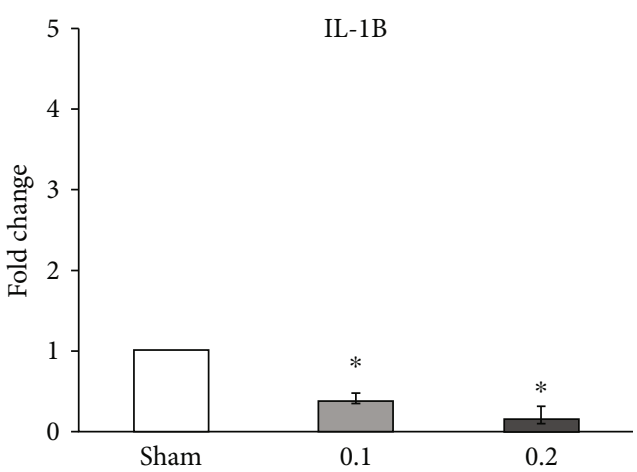

(a)

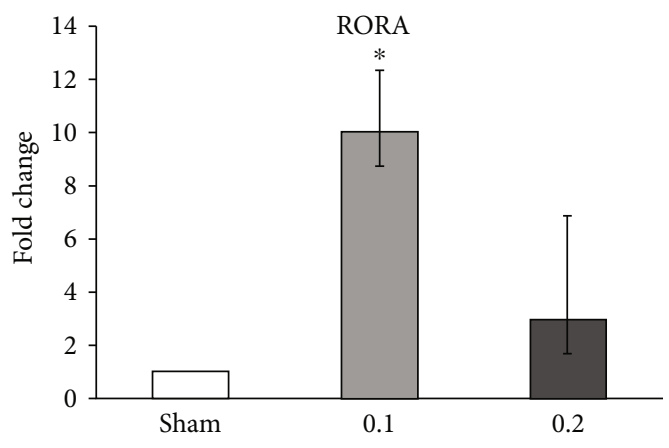

(c)

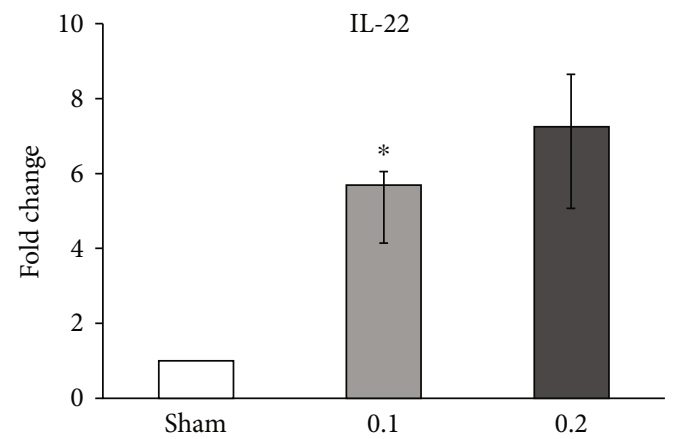

(b)

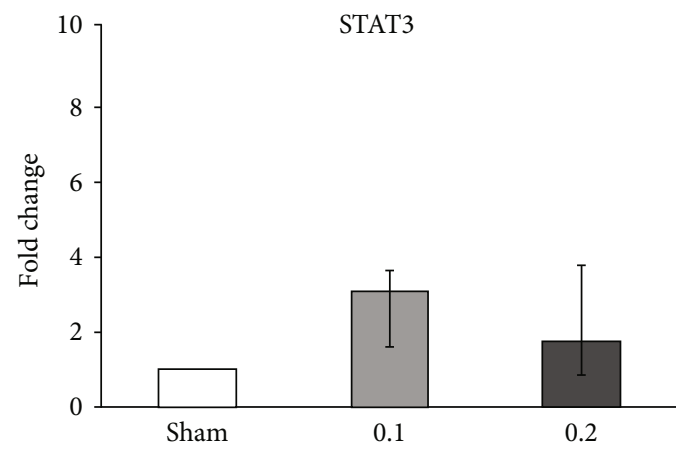

(d)

FIGURE 5: Transcript analysis of interleukin-17 (IL-17) pathway-related markers $(I L-1 B, I L-22$, RORA, and STAT3) in primary bronchial epithelial cells (PBEC) cultured at an air-liquid interface (ALI) condition after $24 \mathrm{~h}$ of incubation following a 30 -minute exposure to clean air (sham), 0.1 or $0.2 \mathrm{ppm}$ acrolein vapor. Transcript expression of interleukin-1 beta (IL-1B), interleukin-22 (IL-22), RAR-related orphan receptor A (RORA), and signal transducer and activator of transcription 3 (STAT3) was analyzed following $24 \mathrm{~h}$ of exposure. Data are presented as median and 25 th-75th percentiles $(N=3$ donors and $n=2$ replicates/donor $) .{ }^{*} p$ value $<0.05$; ${ }^{* *} p$ value $<0.01$; white bars: sham (clean air); light gray bars: $0.1 \mathrm{ppm}$ exposed; dark gray bars: $0.2 \mathrm{ppm}$ acrolein exposed.

TABLE 2: Summary of transcript level changes in oxidative stress, proinflammatory, and tissue injury markers in lung tissue collected from seven mouse strains after subchronic inhalation exposure to acrolein. Numbers indicate the fold change level compared to controls exposed to filtered air.

\begin{tabular}{|c|c|c|c|c|c|c|c|c|c|c|c|c|}
\hline \multirow[t]{2}{*}{ Mouse strains } & \multicolumn{5}{|c|}{ Oxidative stress markers } & \multicolumn{5}{|c|}{ Proinflammatory markers } & \multicolumn{2}{|c|}{$\begin{array}{c}\text { Tissue } \\
\text { injury/repair } \\
\text { markers }\end{array}$} \\
\hline & Gpx1 & $G p \times 3$ & Hmox 1 & $N f k b 1$ & Sod3 & Cxcl1 & $\mathrm{Cxcl} 2$ & $I L-6$ & $I L-17 B$ & $\operatorname{Tnf} \alpha$ & $M m p 9$ & Timp1 \\
\hline $\mathrm{BALB} / \mathrm{cByJ}$ & $2.3^{*}$ & $2.9^{*}$ & 1.7 & $2.7^{*}$ & 1.9 & $2.3^{*}$ & 1.9 & $2.9^{*}$ & $2.7^{*}$ & 1.7 & $2.31^{*}$ & 1.1 \\
\hline C57BL/6J & $5.6^{*}$ & $3.3^{*}$ & 1.8 & $2.8^{*}$ & $3.4^{*}$ & $3.5^{*}$ & $2.8^{*}$ & $3.6^{*}$ & $3.9^{*}$ & $2.3^{*}$ & 1.68 & 2 \\
\hline 129S1/SvImJ & 1.7 & 1.6 & 1.1 & $2.2^{*}$ & 1.5 & $2.9^{*}$ & 1.8 & $4.7^{*}$ & $3.7^{*}$ & 1.8 & 1.1 & 1.7 \\
\hline $\mathrm{DBA} / 2 \mathrm{~J}$ & $2.1^{*}$ & 1.8 & 1.4 & 0.8 & 0.9 & 0.5 & 1.2 & 0.7 & 1.1 & 0.9 & $1.9^{*}$ & $3^{*}$ \\
\hline $\mathrm{C} 3 \mathrm{H} / \mathrm{HeJ}$ & 2.4 & 2.8 & 0.9 & 1.1 & $4.7 *$ & 1.4 & 1.3 & 1.1 & 1.5 & 1.2 & $2.0^{*}$ & $4.6^{*}$ \\
\hline $\mathrm{A} / \mathrm{J}$ & 1.5 & 2.3 & 1.3 & 1.9 & 0.9 & 1.5 & 1.3 & $2.4^{*}$ & 1.9 & 2.5 & 0.9 & 1.8 \\
\hline $\mathrm{FVB} / \mathrm{NJ}$ & $1.9^{*}$ & 1.9 & 0.9 & 0.82 & 1.2 & $2.9^{*}$ & 2.9 & 0.9 & 1.7 & 1.1 & 1.6 & $3.0^{*}$ \\
\hline
\end{tabular}

Glutathione peroxidase 1 (Gpx1), Gpx3; heme oxygenase 1 (Hmox1); superoxide dismutase 3, extracellular (Sod3); nuclear factor of kappa light polypeptide gene enhancer in B cells 1, p105 (Nfkb1); chemokine (C-X-C motif) ligand 1 (Cxcl1), Cxcl2 (aka: macrophage inhibitor protein/ Mip2); interleukin-6 (IL-6), IL-17B; tumor necrosis factor alpha (Tnfo); matrix metallopeptidase 9 (Mmp9); tissue inhibitor of metalloproteinase 1 (Timp1).

BALB/cByJ, C57BL/6J, and 129S1/SvlmJ had the lowest survival time following acute exposure to acrolein among the 40 mouse strains [5]. DBA/2J, C3H/HeJ, A/J, and FVB/NJ were also affected, but to a lesser extent (Figures 1-3). This may be attributed to the upregulation of the tissue injury repair marker Timp1 among these strains (Figure 3).

In spite of similar basal lung transcript levels of the investigated oxidative stress, proinflammatory, and extracellular 
matrix marker genes in sham (control group), acrolein exposure resulted in different response patterns of those genes among the seven mouse strains (Figures 1-3). These interstrain differences in responses suggest that acrolein-induced lung injury may be driven by genetic susceptibility.

Increased lung Nfkb1, Sod3, Gpx1, and Gpx3 transcript expression levels strongly support the onset of oxidative stress due to subchronic acrolein exposure (Figure 1). Several other studies have also demonstrated that reactive oxygen species (ROS) and Tnf can increase the activation of $N f k b 1$ [17-19]. Increased $N f k b 1$ lung transcripts in the acroleinexposed BALB/cByJ, C57BL/6J, and 129S1/SvlmJ mice may cause substantial proinflammatory reactions (Figure 1(e)). The pulmonary $N f k b 1$ signaling pathway serves as a critical modulator for airway hyperresponsiveness to inhaled agents [20], and $N f k b 1$ is a central transcription factor for the production of numerous inflammatory cytokines (Figure 1(e)). $\mathrm{Nfkb} 1$ is also considered as a generic marker of toxic stress which may explain the different patterns of lung $N f k b 1$ expression among the mouse strains compared to other oxidative stress markers [21]. Cheng et al. [22] demonstrated that $N f k b 1$ signaling in nonimmune cells is a critical determinant for the pulmonary response to injurious stimuli and has a great impact on a number of key biological processes, including host defense mechanisms. Different groups have $[20,22]$ reported that the activation of $N f k b 1$ in airway epithelial cells of mice leads to the increased expression of several cytokines and chemokines such as $I L-6, C x c l 1, C x c l 2$, and $I L-17$. Our findings in the lungs of subchronically acrolein-exposed mice are consistent with these studies. It is well established that Nfkb1 is involved in IL-6 production [23, 24 ], and therefore, our findings of simultaneously increased lung $I L-6$ levels in the same mouse strains with increased lung $N f k b 1$ are consistent (Figures 1 and 2). Since IL-17 can also induce IL-6 expression, the pattern of transcript expression in the lungs of acrolein-exposed mouse strains correlates (Figure 2) and supports the validity of the mouse models.

An imbalance of proteinases and antiproteinases and especially Mmp and Timp (Figures 3(a) and 3(b)) is an important feature of the pathogenesis of chronic lung diseases $[25,26]$, and their expression is regulated by various inflammatory markers such as Tnf, IL-6, Cxcl1 [27, 28], and Cxcl2. Therefore, the findings of the present study, i.e., increased $M m p 9$ along with unaltered Timp1 transcript expression in the acrolein-exposed BALB/cByJ strain, indicate susceptibility to acrolein (Figures 3(a) and 3(b)). Thus, low levels of Timpl can cause increased sensitivity to acrolein and other chemical irritants. However, in the more resistant strains (DBA/2J, C3H/HeJ, and FVB/NJ), both Mmp9 and Timp1 were upregulated suggesting a level protease-antiprotease balance to counter tissue injury (Figures 3(a) and 3(b)). Upregulation of $I L-17 B$ in the lungs of the more susceptible strains (i.e., BALB/cByJ, C57BL/6J, and 129S1/SvlmJ, Figure 2(d)) is an important observation. The IL-17 pathway has been recognized as a proinflammatory cytokine pathway involved in chronic airway inflammation among asthmatics $[29,30]$. Data suggesting a role for IL-17 in tobacco smoke-induced lung diseases, including COPD, has also emerged $[31,32]$. Acrolein is a major component of tobacco smoke. It is plausible that the increased transcript expression of $I L-17 B$ detected in mouse lungs may be due to the stimulation of resident CD4+ cells by proinflammatory cytokines such as IL-6, Cxcl1, Cxcl2, and Tnf as described by Wang et al. [30]. This led us to investigate the IL-17 pathway genes in more detail in the PBEC-ALI model following exposure to 0.1 and $0.2 \mathrm{ppm}$ acrolein.

Increased expression of $I L-17 A, C$, and $D$ in the bronchial mucosa model following $0.1 \mathrm{ppm}$ acrolein exposure (Figures 4(a)-4(e)) indicates the plausible airway inflammation that may be caused by low-dose acrolein exposures relevant for the onset of chronic lung diseases such as asthma and COPD. Increased expression of $I L-1 B, I L-22$, and RORAv (Figures 5(a)-5(c)) following acrolein exposure further demonstrates IL-17 as a candidate pathway for low-dose acrolein exposure-mediated airway effects. It is plausible that IL-17 is indirectly triggered by cells damaged by acrolein and IL-17 may have a central role in the response to chemical irritants. Mechanistic studies focused on the role of IL-17 to other aldehydes will enhance our understanding in this aspect.

To summarize, our study utilized 7 inbred mouse strains (female) that are commonly used in respiratory research and demonstrated that subchronic exposure to low-dose (1 ppm) acrolein does not result in transient neutrophilia and lung injury. However, it does induce significant and strainselective changes in the expression of several oxidative stress, proinflammatory, and tissue injury/repair markers leading to the identification of sensitive and resistant mouse strains for use in genetic susceptibility studies. Consistent findings of a simultaneous increase in lung $N f k b 1, I l 6$, and $I L-17 B$ within the same acrolein-exposed mouse strains support the validity of the models. The findings also indicate that genetically determined differences in IL-17 signaling pathway genes in the different mouse strains may explain their susceptibility to different chemical irritants. On the basis of our mouse studies, we have further investigated the effects of low-dose acrolein exposure on PBEC cultured at ALI and thus identified IL-17 as a candidate pathway for low-dose acroleininduced effects in human primary bronchial epithelial cells cultured at an air-liquid interface. Moreover, our findings implicate that low-dose acrolein exposure impairs the innate immune response in the airways which may in turn result in a predisposition to chronic lung diseases such as asthma and COPD. Therefore, it is plausible that IL-17 plays a central role in chemical irritants and it will be important to elucidate if the IL-17 pathway has a specific role in acrolein-mediated toxicity through mechanistic and functional studies.

\section{Data Availability}

All data required to comprehend the manuscript have been provided in the manuscript's main body and supplementary material. All raw data are available from the corresponding author.

\section{Ethical Approval}

The study was approved by the ethics committee at Karolinska Institutet, Stockholm, Sweden, and by the Institutional Animal Care and Use Committee, New York University, School of Medicine (NY, USA). 


\section{Disclosure}

Some contents of this manuscript have been presented in the form of an abstract titled "Identification of IL-17 Pathway as a Plausible Target for Pulmonary Effects following Acrolein Exposure Studies on Inbred Mouse Strains and Human Primary Bronchial Epithelial Cells at Air-Liquid Interface" at the Annual Conference of Society of Toxicology 2020, https://www.toxicology.org/pubs/docs/Tox/2020Tox.pdf.

\section{Conflicts of Interest}

The authors declare that they have no conflict of interests.

\section{Authors' Contributions}

GJ, LP, KG (Koustav Ganguly), TG, and SU conceived and designed the project; SU, AMD, LCC, LE, and KG (Karen Galdanes) performed the experiments; SU, AMD, LE, and KG (Koustav Ganguly) analyzed the data; GJ, LP, KG (Koustav Ganguly), TG, and SU wrote the manuscript. All authors have read and approved the manuscript.

\section{Acknowledgments}

The authors sincerely acknowledge the trained animal caregiver who assisted in the mouse exposure study. This study is supported by Working Life and Welfare (FORTE: 20130044), the Swedish Hjärt-Lungfonden (20100180, 20120376, 20120818, 20150328, 20150329, and 20150330), and the Karolinska Institutet (2016fobi4760), Sweden.

\section{Supplementary Materials}

Mouse lung transcript expression analysis following acrolein exposure. Acrolein exposure of the ALI model. Table S1: list of primer pairs used for transcript expression analysis using quantitative real-time polymerase chain reaction. Table S2: bronchoalveolar lavage cell differentials of seven mouse strains after subchronic inhalation exposure to filtered air (sham) and acrolein. Table S3: total concentration of protein in bronchoalveolar lavage of seven mouse strains after subchronic inhalation exposure to filtered air (sham) and acrolein. (Supplementary Materials)

\section{References}

[1] D. J. Conklin, M. V. Malovichko, I. Zeller et al., "Biomarkers of chronic acrolein inhalation exposure in mice: implications for tobacco product-induced toxicity," Toxicological Sciences, vol. 158, no. 2, pp. 263-274, 2017.

[2] Bein and Leikauf, "Acrolein - a Pulmonary Hazard," Molecular Nutrition \& Food Research, vol. 55, no. 9, pp. 1342-1360, 2011.

[3] D. I. Kasahara, M. E. Poynter, Z. Othman, D. Hemenway, and A. van der Vliet, "Acrolein inhalation suppresses lipopolysaccharide-induced inflammatory cytokine production but does not affect acute airways neutrophilia," Journal of Immunology, vol. 181, no. 1, pp. 736-745, 2008.

[4] S. V. Raju, P. L. Jackson, C. A. Courville et al., "Cigarette smoke induces systemic defects in cystic fibrosis transmembrane conductance regulator function," American Journal of Respiratory and Critical Care Medicine, vol. 188, no. 11, pp. 1321-1330, 2013.

[5] G. D. Leikauf, V. J. Concel, P. Liu et al., "Haplotype association mapping of acute lung injury in mice implicates activin a receptor, type 1," American Journal of Respiratory and Critical Care Medicine, vol. 183, no. 11, pp. 1499-1509, 2011.

[6] M. T. Borchers, M. P. Carty, and G. D. Leikauf, "Regulation of human airway mucins by acrolein and inflammatory mediators," The American Journal of Physiology, vol. 276, no. 4, pp. L549-L555, 1999.

[7] A. J. A. McGuinness and E. Sapey, "Oxidative stress in COPD: sources, markers, and potential mechanisms," Journal of Clinical Medicine, vol. 6, no. 2, p. 21, 2017.

[8] M. M. Bradford, "A rapid and sensitive method for the quantitation of microgram quantities of protein utilizing the principle of protein-dye binding," Analytical Biochemistry, vol. 72, no. 1-2, pp. 248-254, 1976.

[9] S. C. Wesselkamper, L. C. Chen, and T. Gordon, "Development of pulmonary tolerance in mice exposed to zinc oxide fumes," Toxicological Sciences, vol. 60, no. 1, pp. 144-151, 2001.

[10] A. M. Dwivedi, S. Upadhyay, G. Johanson, L. Ernstgård, and L. Palmberg, "Inflammatory effects of acrolein, crotonaldehyde and hexanal vapors on human primary bronchial epithelial cells cultured at air-liquid interface," Toxicology in Vitro, vol. 46, pp. 219-228, 2018.

[11] J. Ji, A. Hedelin, M. Malmlöf et al., "Development of combining of human bronchial mucosa models with Xpose $A L I^{\circledR}$ for exposure of air pollution nanoparticles," PLoS One, vol. 12, no. 1, article e0170428, 2017.

[12] T. A. Thimraj, S. I. Sompa, K. Ganguly et al., "Evaluation of diacetyl mediated pulmonary effects in physiologically relevant airliquid interface models of human primary bronchial epithelial cells," Toxicology in Vitro, vol. 61, article 104617, 2019.

[13] K. Strandberg, L. Palmberg, and K. Larsson, "Effect of budesonide and formoterol on Il-6 and Il-8 release from primary bronchial epithelial cells," The Journal of Asthma, vol. 45, no. 3, pp. 201-203, 2008.

[14] I. von Scheele, K. Larsson, and L. Palmberg, "Budesonide enhances toll-like receptor 2 expression in activated bronchial epithelial cells," Inhalation Toxicology, vol. 22, no. 6, pp. 493499, 2010.

[15] S. Zhu and Y. Qian, "Il-17/Il-17 receptor system in autoimmune disease: mechanisms and therapeutic potential," Clinical science, vol. 122, no. 11, pp. 487-511, 2012.

[16] L. Li and A. Holian, "Acrolein: a respiratory toxin that suppresses pulmonary host defense," Reviews on environmental health, vol. 13, no. 1-2, pp. 99-108, 1998.

[17] I. Rahman, "Oxidative stress and gene transcription in asthma and chronic obstructive pulmonary disease: antioxidant therapeutic targets," Current Drug Targets. Inflammation and Allergy, vol. 1, no. 3, pp. 291-315, 2002.

[18] I. Rahman, J. Marwick, and P. Kirkham, "Redox modulation of chromatin remodeling: impact on histone acetylation and deacetylation, NF- $\kappa \mathrm{B}$ and pro-inflammatory gene expression," Biochemical Pharmacology, vol. 68, no. 6, pp. 1255-1267, 2004.

[19] W. vanden Berghe, K. de Bosscher, E. Boone, S. Plaisance, and G. Haegeman, “The nuclear Factor- $\kappa$ B engages Cbp/P300 and histone acetyltransferase activity for transcriptional activation of the interleukin-6 gene promoter," Journal of Biological Chemistry, vol. 274, no. 45, pp. 32091-32098, 1999. 
[20] J. R. Sheller, V. V. Polosukhin, D. Mitchell, D.-S. Cheng, R. S. Peebles, and T. S. Blackwell, "Nuclear factor kappa B induction in airway epithelium increases lung inflammation in allergenchallenged mice," Experimental Lung Research, vol. 35, no. 10, pp. 883-895, 2009.

[21] K. Lingappan, "NF- $\kappa$ B in oxidative stress," Current opinion in toxicology, vol. 7, pp. 81-86, 2018.

[22] D.-s. Cheng, W. Han, S. M. Chen et al., “Airway epithelium controls lung inflammation and injury through the Nf-kappa B pathway," The Journal of Immunology, vol. 178, no. 10, pp. 6504-6513, 2007.

[23] T. A. Libermann and D. Baltimore, "Activation of interleukin6 gene expression through the NF-kappa B transcription factor," Molecular and cellular biology, vol. 10, no. 5, pp. 2327-2334, 1990.

[24] T. Liu, L. Zhang, D. Joo, and S.-C. Sun, "NF- $\kappa$ B signaling in inflammation," Signal Transduction and Targeted Therapy, vol. 2, no. 1, article 17023, 2017.

[25] H. S. Deshmukh, C. Shaver, L. M. Case et al., "Acrolein-activated matrix metalloproteinase 9 contributes to persistent mucin production," American journal of respiratory cell and molecular biology, vol. 38, no. 4, pp. 446-454, 2008.

[26] S. D. Shapiro and E. P. Ingenito, "The pathogenesis of chronic obstructive pulmonary disease: advances in the past 100 years," American Journal of Respiratory Cell and Molecular Biology, vol. 32, no. 5, pp. 367-372, 2005.

[27] R. N. Johnatty, D. D. Taub, S. P. Reeder et al., "Cytokine and chemokine regulation of Prommp-9 and Timp-1 production by human peripheral blood lymphocytes," The Journal of Immunology, vol. 158, no. 5, pp. 2327-2333, 1997.

[28] A. E. Kossakowska, D. R. Edwards, C. Prusinkiewicz et al., "Interleukin-6 regulation of matrix metalloproteinase (Mmp-2 and Mmp-9) and tissue inhibitor of metalloproteinase (Timp-1) expression in malignant non-Hodgkin's lymphomas," Blood, vol. 94, no. 6, pp. 2080-2089, 1999.

[29] A. Lindén and B. Dahlén, "Interleukin-17 cytokine signalling in patients with asthma," The European Respiratory Journal, vol. 44, no. 5, pp. 1319-1331, 2014.

[30] Y.-H. Wang and M. Wills-Karp, "The Potential Role of Il-17 in Severe Asthma," Current Allergy and Asthma Reports, vol. 11, no. 5, pp. 388-394, 2011.

[31] S. Bozinovski, H. J. Seow, S. P. J. Chan et al., "Innate cellular sources of interleukin-17a regulate macrophage accumulation in cigarette- smoke-induced lung inflammation in mice," Clinical Science (London, England), vol. 129, no. 9, pp. 785-796, 2015.

[32] A. Strzelak, A. Ratajczak, A. Adamiec, and W. Feleszko, "Tobacco smoke induces and alters immune responses in the lung triggering inflammation, allergy, asthma and other lung diseases: a mechanistic review," International journal of environmental research and public health, vol. 15, no. 5, 2018. 